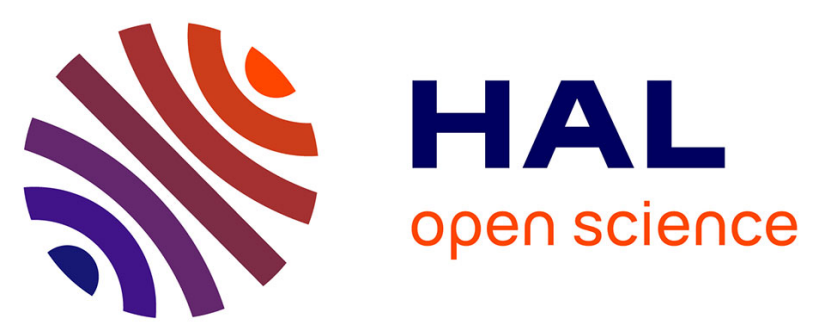

\title{
Effect of cerium on structure modifications of a hybrid sol-gel coating, its mechanical properties and anti-corrosion behavior
}

Jean-Baptiste Cambon, Julien Esteban, Florence Ansart, Jean-Pierre Bonino, Viviane Turq, Silvia Helena Santagneli, Celso Valentin Santilli, Sandra Helena

\author{
Pulcinelli
}

\section{To cite this version:}

Jean-Baptiste Cambon, Julien Esteban, Florence Ansart, Jean-Pierre Bonino, Viviane Turq, et al.. Effect of cerium on structure modifications of a hybrid sol-gel coating, its mechanical properties and anti-corrosion behavior. Materials Research Bulletin, 2012, vol. 47, pp. 3170-3176. 10.1016/j.materresbull.2012.08.034 . hal-00837994

\section{HAL Id: hal-00837994 https://hal.science/hal-00837994}

Submitted on 24 Jun 2013

HAL is a multi-disciplinary open access archive for the deposit and dissemination of scientific research documents, whether they are published or not. The documents may come from teaching and research institutions in France or abroad, or from public or private research centers.
L'archive ouverte pluridisciplinaire HAL, est destinée au dépôt et à la diffusion de documents scientifiques de niveau recherche, publiés ou non, émanant des établissements d'enseignement et de recherche français ou étrangers, des laboratoires publics ou privés. 


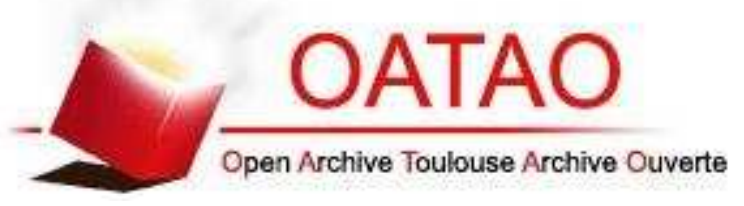

\section{Open Archive Toulouse Archive Ouverte (OATAO)}

OATAO is an open access repository that collects the work of Toulouse researchers and makes it freely available over the web where possible.

This is an author-deposited version published in: http://oatao.univ-toulouse.fr/ Eprints ID: 8736

To link to this article: DOI: $10.1016 /$ j.materresbull.2012.08.034

Official URL: http://dx.doi.org/10.1016/j.materresbull.2012.08.034

\section{To cite this version:}

Cambon, Jean-Baptiste and Esteban, Julien and Ansart, Florence and Bonino, Jean-Pierre and Turq, Viviane and Santagneli, Silvia Helena and Santilli, Celso Valentin and Pulcinelli, Sandra Helena Effect of cerium on structure modifications of a hybrid sol-gel coating, its mechanical properties and anticorrosion behavior. (2012) Materials Research Bulletin, vol. 47 ( $\left.\mathrm{n}^{\circ} 11\right)$. pp. 3170-3176. ISSN 0025-5408

Any correspondence concerning this service should be sent to the repository administrator: staff-oatao@inp-toulouse.fr 


\title{
Effect of cerium on structure modifications of a hybrid sol-gel coating, its mechanical properties and anti-corrosion behavior
}

\author{
Jean-Baptiste Cambon ${ }^{\mathrm{a}, *}$, Julien Esteban ${ }^{\mathrm{a}}$, Florence Ansart ${ }^{\mathrm{a}}$, Jean-Pierre Bonino ${ }^{\mathrm{a}}$, Viviane Turq $^{\mathrm{a}}$, \\ S.H. Santagneli ${ }^{\text {b }, ~ C . V . ~ S a n t i l l i ~}{ }^{\text {b }}$, S.H. Pulcinelli ${ }^{\mathrm{b}}$ \\ a Institut Carnot CIRIMAT, Université de Toulouse, UMR CNRS 5085, 118 Route de Narbonne, 31062 Toulouse Cedex 9, France \\ ${ }^{\mathrm{b}}$ Departamento Fisico-Química, Instituto de Química, Universidade Estadual Paulista, UNESP, CP 355, 14801-970 Araraquara, SP, Brazil
}

\begin{abstract}
A B S T R A C T
An organic-inorganic hybrid coating was developed to improve the corrosion resistance of the aluminum alloy AA 2024-T3. Organic and inorganic coatings derived from glycidoxypropyltrimethoxysilane (GPTMS) and aluminum tri-sec-butoxide $\mathrm{Al}\left(\mathrm{O}^{\mathrm{s}} \mathrm{Bu}\right)_{3}$, with different cerium contents, were deposited onto aluminum by dip-coating process. Corrosion resistance and mechanical properties were investigated by electrochemical impedance measurements and nano-indentation respectively. An optimal cerium concentration of $0.01 \mathrm{M}$ was evidenced. To correlate and explain the hybrid coating performances in relation to the cerium content, NMR experiments were performed. It has been shown that when the cerium concentration in the hybrid is higher than $0.01 \mathrm{M}$ there are important modifications in the hybrid structure that account for the mechanical properties and anti-corrosion behavior of the sol-gel coating.
\end{abstract}

Keywords:

A. Hydrides

B. Sol-gel chemistry

C. Nuclear magnetic resonance (NMR)

D. Impedance spectroscopy

E. Electrochemical properties

F. Mechanical properties

\section{Introduction}

Aluminum alloys, especially AA 2024-T3, are characterized by high mechanical strength and relative low weight, providing suitable properties for the aircraft industry [1]. However, the presence of intermetallic compounds, which can act either as anodic or cathodic regions, makes aluminum alloys more sensitive to localized corrosion after exposure in aggressive environments [2,3]. Historically, chromate conversion coatings were used to prevent corrosion of aluminum alloys. But the presence of toxic hexavalent chromium compounds makes those coatings very hazardous to the environment. Consequently, it is necessary to develop new environmentally compliant chromate (VI)-free alternatives. A new promising approach consists to use sol-gel process to prepare hybrid protective coatings [4,5]; thus, sol-gel films were highly investigated from the last decade as possible candidates for environmentally friendly treatments on metals [5-8].

Sol-gel route consists in both hydrolysis and condensation of metal alkoxides, contained in a liquid solution, called sol, to obtain metaloxane network [8-10]. The progress of condensation reactions finally leads to the formation of a dense hybrid network. Commonly,

\footnotetext{
* Corresponding author. Tel.: +33 0561557871; fax: +33 0561556163.

E-mail address: cambon@chimie.ups-tlse.fr (J.-B. Cambon).
}

sol-gel processes involve silane precursors as starting materials. Silane based coatings usually exhibit good barrier properties due to the development of a dense -Si-O-Si- network [11-15], which inhibits the penetration of aggressive species towards the metallic substrate. Thus, the efficiency of the metal surface pre-treatments based on silane coatings is strongly dependent on the barrier properties of the film $[16,17]$. However, when a defect is formed in the barrier layer, the coating is not able to stop the localized corrosion process. Thus, the presence of inhibitor species is essential to decrease or to avoid corrosion activity in these cases [18]. Recently, different inhibitors have been studied to prevent corrosion of metal surfaces. Cerium compounds appeared, through lot of works, as a promising corrosion inhibitor to replace chromate compounds for the corrosion protection of various metallic compounds, especially aluminum alloys [19-24].

The aim of this paper consists, first, in the characterization of both microstructure and barrier effect of an alumino-silane hybrid sol-gel coating. Then cerium nitrate has been introduced into the hybrid sol-gel layer in order to improve the corrosion protection. The cerium nitrate was added at different ratios in the sol to understand the possible interactions of the inhibitor with components of the sol-gel system. Anti-corrosion protection and mechanical properties of alumino-silane hybrid coating containing different cerium contents were evaluated, depending on cerium content, by electrochemical analyses (EIS) and nanoindentation. Finally, ${ }^{29} \mathrm{Si},{ }^{13} \mathrm{C}$ and ${ }^{27} \mathrm{Al} \mathrm{RMN}$ analyzes were 


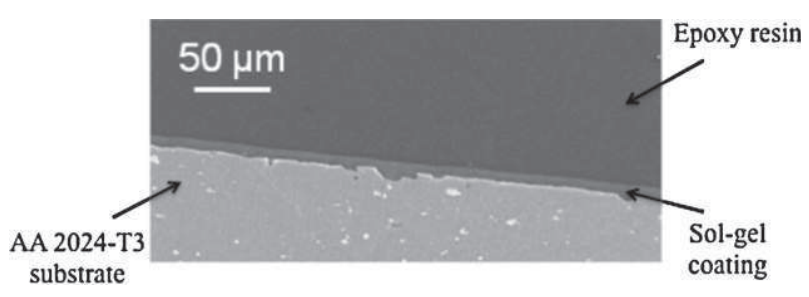

Fig. 1. Micrograph of a sol-gel film deposited on AA 2024-T3 using a cross-section view.

performed in order to understand how cerium interacts with the other components and how it integrates the hybrid network.

\section{Experimental}

The composition of the AA 2024-T3 aluminum alloy is described in Table 1.

Each sample surface $(80 \mathrm{~mm} \times 42 \mathrm{~mm} \times 1 \mathrm{~mm})$ was first cleaned and degreased in acetone. Then, a chemical pretreatment is needed before sol deposition in order to improve hybrid coating adhesion. It was performed as follows: an immersion in a $\mathrm{NaOH}$ bath maintained at $60^{\circ} \mathrm{C}$, followed by rinsing with deionized water; a neutralization in an acidified solution of $\mathrm{NaNO}_{3}$, at room temperature. The samples were finally washed in ethanol and dried in air.Sols were prepared by mixing glycidoxypropyltrimethoxysilane (GPTMS) (Fig. 1) and aluminum tri-sec-butoxide $\mathrm{Al}\left(\mathrm{O}^{\mathrm{s}} \mathrm{Bu}\right)_{3}$ (Fig. 2) with distilled water and propanol in molar ratio $5: 1: 10: 12$. Then $\mathrm{Ce}\left(\mathrm{NO}_{3}\right)_{3} \cdot 6 \mathrm{H}_{2} \mathrm{O}$ was added to investigate the cerium range: $0-0.1 \mathrm{M}$. Then, the obtained sol was stirred during 2 hours at room temperature and aged for 24 hours before deposition on the substrate.Sol-gel films were obtained by dipcoating process, using an immersion step followed by a withdrawal at a controlled rate of $20 \mathrm{~cm} \mathrm{~min}^{-1}$. After deposition, coated samples were dried at $110^{\circ} \mathrm{C}$ during 24 hours.
The microstructures of the coatings were observed by scanning electron microscopy (SEM) on a JEOL JSM-6060 device.

The electrochemical behavior of the systems was evaluated by electrochemical impedance spectroscopy (EIS) in a $0.05 \mathrm{M} \mathrm{NaCl}$ static solution $(\mathrm{pH}=6.0)$. For the electrochemical measurements, a three-electrode electrochemical cell was used, consisting of a platinum counter electrode, a saturated calomel reference electrode and the sample was used as a working electrode, with an exposed area equal to $15 \mathrm{~cm}^{2}$. The experimental apparatus used for the electrochemical investigation was a potentiostat (AUTOLAB PGSTAT 30) and a frequency response analyzer (FRA). EIS measurements were performed in potentiostatic mode at the OCP, obtained after a 1 hour stabilization of the potential in the electrolyte. The amplitude of the EIS perturbation signal was $10 \mathrm{mV}$, and the frequency studied ranged from $100 \mathrm{kHz}$ to $10 \mathrm{mHz}$.

The mechanical properties of the films were conducted using a UltraNanoHardness Tester machine from CSMb Instruments (Switzerland). Young's modulus $E$ and nano-hardness $H$ of each film were measured with a Berkovich three-sided pyramid diamond indenter. The Poisson ratio of the hybrid coatings was taken at a value of $v=0.3$. Experiments were performed in a laboratory air environment at ambient temperature. In all CSM nano-indentation tests, a total of five indents were averaged to determine the mean Young's modulus and nano-hardness, $E$ and $H$ values for statistical purposes. The calibration and analysis procedure suggested by Oliver and Pharr [25] was used to correct for the load-frame compliance of the apparatus and the imperfect shape of the indenter tip and to determine hardness and elastic modulus. The area function $A(h c)$ was calibrated on fused silica and relates the contact area to the contact depth $h c$. Data of hardness and elastic modulus of various films [26] and coating deposited using the sol-gel route [27] from experimental data using this technique can be found in the literature. The maximal normal force was $100 \mu \mathrm{N}$, the loading rate is $1 \mu \mathrm{N} \mathrm{s}^{-1}$ and the penetration depth was kept under $100 \mathrm{~nm}$ in order to avoid substrate influence.

Table 1

Chemical composition of the AA 2024-T3 aluminum alloy.

\begin{tabular}{|c|c|c|c|c|c|c|c|c|}
\hline & \multicolumn{8}{|l|}{ Element } \\
\hline & $\mathrm{Si}$ & $\mathrm{Fe}$ & $\mathrm{Cu}$ & Mn & $\mathrm{Mg}$ & $\mathrm{Zn}$ & $\mathrm{Ti}$ & $\mathrm{Al}$ \\
\hline wt\% & $0.06-0.09$ & $0.14-0.16$ & $4.1-4.6$ & $0.49-0.57$ & $1.37-1.40$ & 0.15 & 0.02 & Balance \\
\hline
\end{tabular}
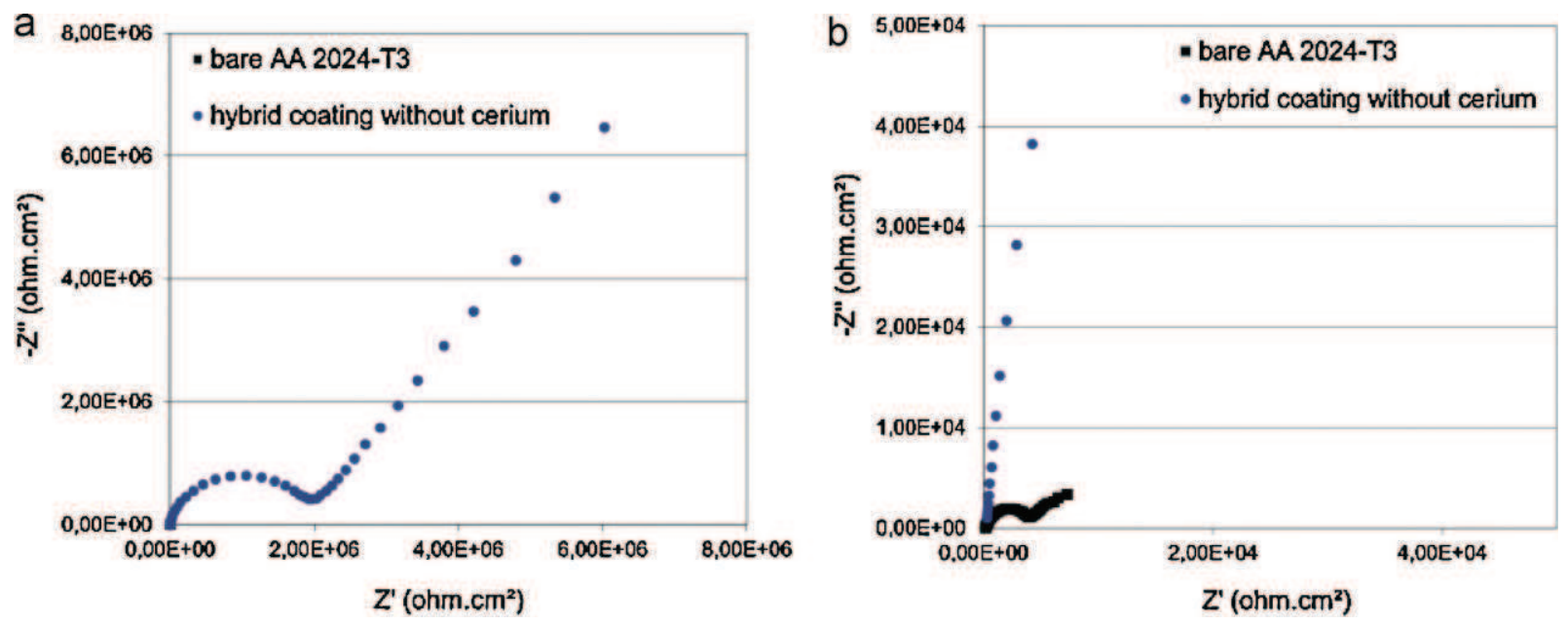

Fig. 2. Nyquist diagrams obtained after 1 hour in a $0.05 \mathrm{M} \mathrm{NaCl}$ solution, for uncoated and coated 2024-T3 aluminum alloy. 
Solid-state ${ }^{29} \mathrm{Si},{ }^{13} \mathrm{C}$ and ${ }^{27} \mathrm{Al}$ magic-angle spinning nuclear magnetic resonance (MAS/NMR) spectra were recorded for unsupported hybrid films using a VARIAN spectrometer operating at $300 \mathrm{MHz}$ and $7.05 \mathrm{~T}$. The Larmor frequency for ${ }^{29} \mathrm{Si},{ }^{13} \mathrm{C}$ and ${ }^{27} \mathrm{Al}$ were $59.59 \mathrm{MHz}, 75.42 \mathrm{MHz}$ and $78.16 \mathrm{MHz}$, respectively. The spectra were obtained from the Fourier transformation of the free induction decays (FID) following a single $\pi / 2$ excitation pulse and a dead time of $2 \mathrm{~s}$. Chemical shifts were referenced to tetramethylsilane (TMS), used as external standard. Proton decoupling was always used during spectra acquisition. Because of the high sensitivity of the ${ }^{29} \mathrm{Si},{ }^{13} \mathrm{C}$ and ${ }^{27} \mathrm{Al}$ NMR measurements, the accuracy in the chemical shift values was of $0.2 \mathrm{ppm}$.

The real densities of each unsupported hybrid film were determined by using a helium pycnometer (Accupyc 1330 Micromeritics).

\section{Results and discussion}

\subsection{Morphological characterization of the film}

Fig. 1 shows a cross section of the hybrid coating, elaborated on 2024-T3 aluminum alloy substrate.

It can be seen that the film is homogeneous and around $5 \mu \mathrm{m}$ thick. The sol-gel layer has a leveling effect and no defects are visible at the microscopic scale.

\subsection{Coating properties}

\subsubsection{Electrochemical characterization}

Fig. 4 displays Nyquist diagrams obtained after 1 hour of immersion in a $0.05 \mathrm{M} \mathrm{NaCl}$ solution for uncoated and coated 2024-T3 aluminum alloy without cerium. The high resistance values (Fig. 2a) observed after 1 hour of immersion indicate the

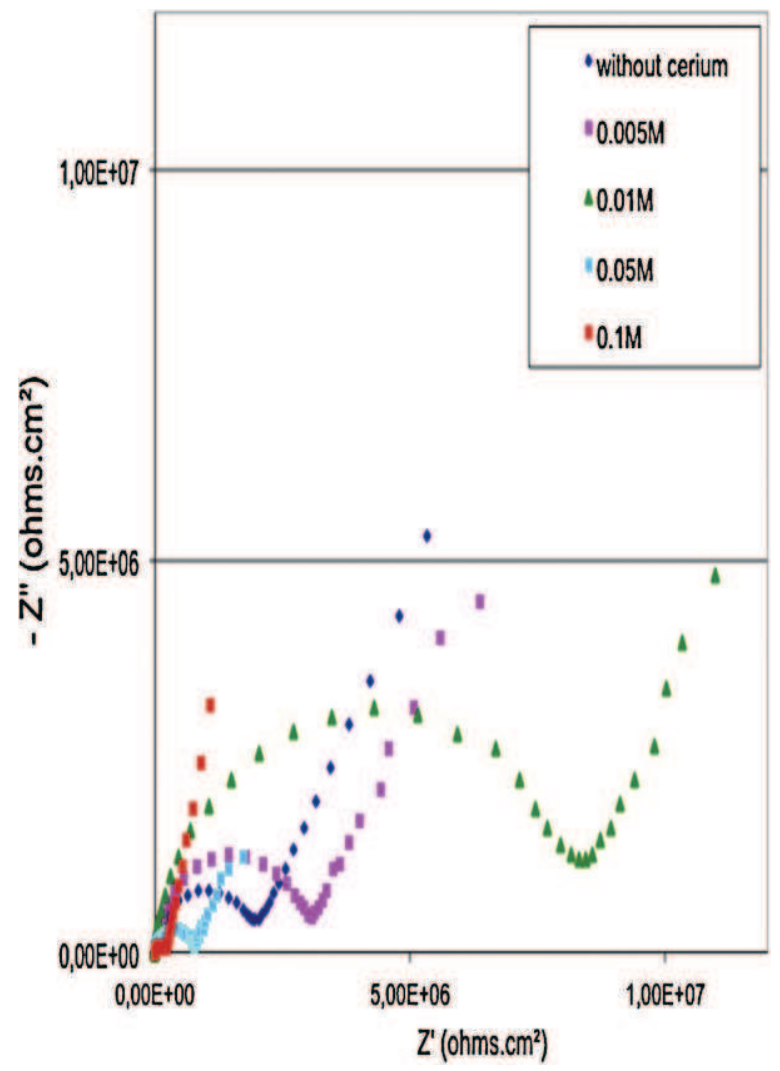

Fig. 3. Nyquist diagram obtained after 1 hour in a $0.05 \mathrm{M} \mathrm{NaCl}$ solution, for different cerium concentrations added into the sol.

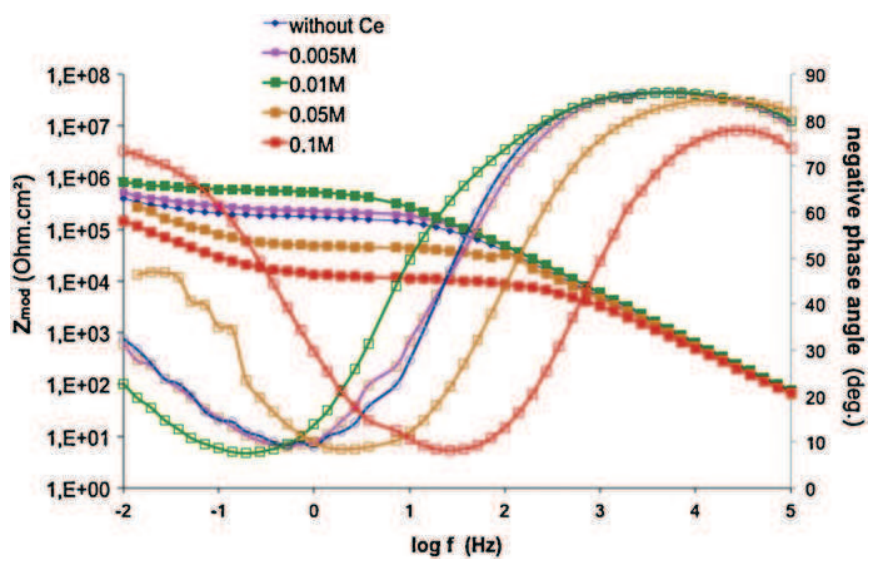

Fig. 4. Bode diagram obtained after 1 hour in a $0.05 \mathrm{M} \mathrm{NaCl}$ solution, for different cerium concentrations added into the sol.

higher resistance of coated sample, compared to uncoated aluminum alloy (Fig. 2b). However, the exposure to Neutral Salt Spray (ASTM B117) of coated samples revealed the apparition of corrosion pits after 200 hours. Corrosion apparition could result from initial defects of the hybrid coating or damage during the corrosion test, inducing the corrosion of the aluminum substrate. In order to improve the corrosion resistance for a long term, and to add an active corrosion protection to the hybrid sol-gel coating, cerium has been incorporated into the sol-gel matrix.

Fig. 3 displays Nyquist diagrams obtained after 1 hour of immersion in a $0.05 \mathrm{M} \mathrm{NaCl}$ solution for 2024-T3 aluminum alloy coated with hybrid films containing different cerium concentrations. Results underline that the addition of a low concentration of cerium into the hybrid films increases the resistance of the protective coatings. However, when the cerium concentration exceeds $0.01 \mathrm{M}$, a strong decrease of the resistance of the coating is observed, and the higher the cerium content, the greater the degradation of the barrier properties. We can suggest that this behavior would be due to the incorporation of bigger cations into the hybrid network inducing the partial destabilization of the system at the highest cerium concentrations, leading to the decrease of the layer barrier effect. This point will be discussed later.

Furthermore, we studied the evolution of the impedance modulus, using Bode diagram (Fig. 4). The resistive plateau at middle frequencies is representative to the resistance of the alumino-silane hybrid coating, i.e. the resistance of the electrolyte into the pores [28-32]. On the first hand, the pore resistance suggests that the most efficient barrier effect is obtained for an optimal cerium concentration of $0.01 \mathrm{M}$, confirming previously made conclusions based on Nyquist diagrams interpretation. On the other hand, lower barrier effect values are obtained for higher cerium contents.

We can also underline, on Bode diagram, relative to phase angle evolutions, a phenomenon at high frequencies $\left(\approx 10^{3} \mathrm{~Hz}\right)$, associated with both capacitance and resistance of alumino-silane hybrid coating [5,32-36]. The high angle values, closed to $90^{\circ}$, suggest an efficient barrier effect whatever the cerium concentration of the coatings. Moreover for cerium concentrations beyond $0.01 \mathrm{M}$, a decrease of phase angle values and a shift of the barrier effect towards higher frequencies were noted. This behavior can be associated $[35,37,38]$ to a more important penetration of the electrolyte through the coating, which could be due, in our case to the partial destabilization of the hybrid network for high cerium concentrations. This result confirms that cerium addition, above $0.01 \mathrm{M}$, probably generates physico-chemical changes, and can induce structural modifications of the hybrid network. This 

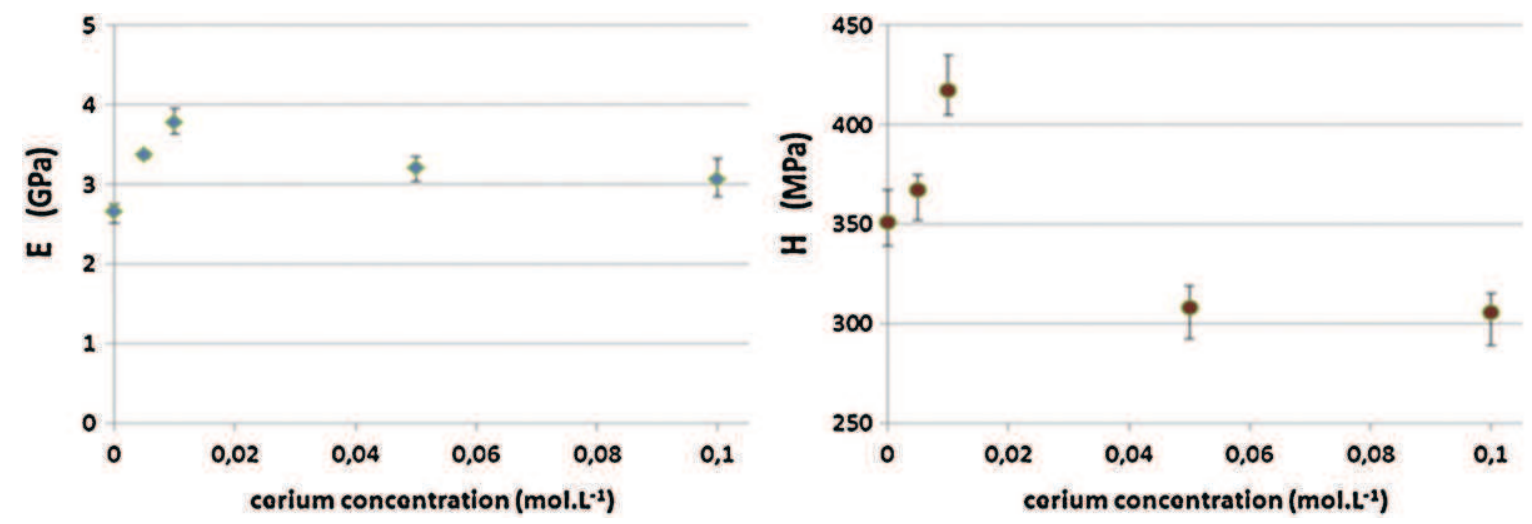

Fig. 5. Evolution of elastic and hardness modulus for different cerium concentrations added into the sol.

hypothesis can be confirmed by the presence of another phenomenon, noted at low frequencies $\left(\approx 10^{-1} \mathrm{~Hz}\right)$ on the phase angle evolution for the two higher cerium concentrations ( 0.05 and $0.1 \mathrm{M})$. Indeed, this new time constant can be correlated to the presence of the corrosion activity on the substrate $[4,5,36,13,39-$ 41]. It is possible to note that the phenomenon is more important for the higher values of cerium concentration $(0.1 \mathrm{M})$.

The electrochemical results indicate that, in controlled proportions, the addition of cerium leads to the increase the barrier effect, and thus the anti-corrosion properties, probably by reinforcing the inorganic network. However, there is a threshold (up to $0.01 \mathrm{M}$ ) in the cerium content addition and it was observed that high cerium concentrations reduce the initial barrier effect of the hybrid film and lead to corrosion process. These phenomena are probably due to the physico-chemical changes in the hybrid network and internal constraints. In order to check this hypothesis, nanoindentation tests were performed on hybrid coatings containing different cerium concentrations.

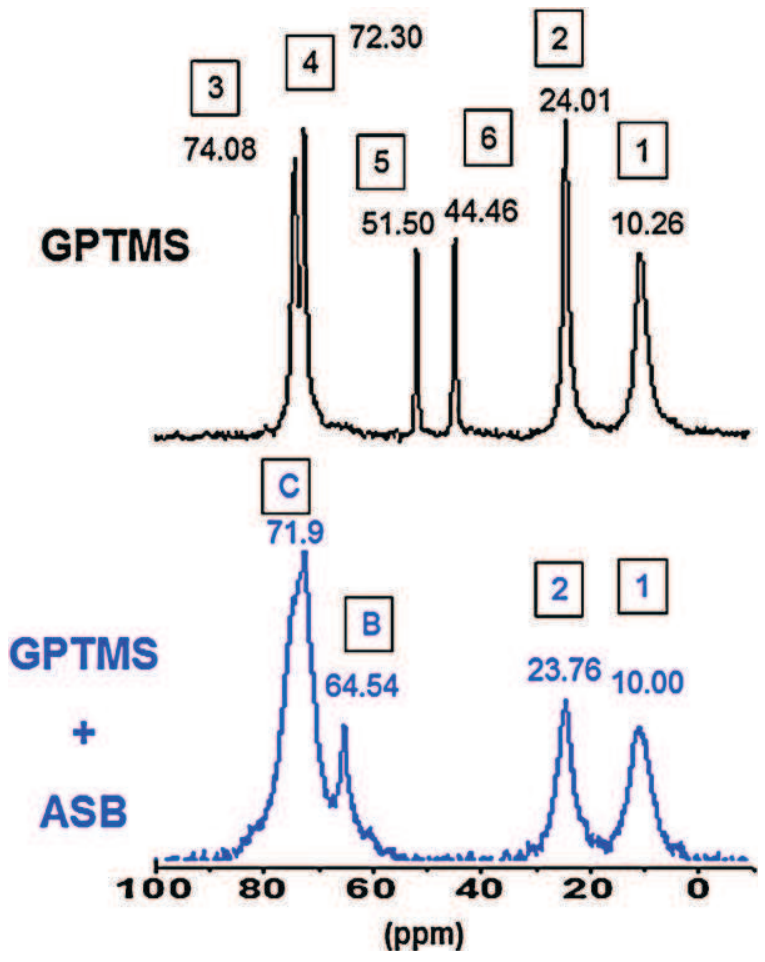

Fig. 6. ${ }^{13} \mathrm{C}$ MAS/NMR spectra of hybrids: GPTMS and GPTMS/ASB.

\subsubsection{Mechanical properties}

The evolution of elastic and hardness modulus with the cerium content in the coating is reported in Fig. 5. First, it is clear that the hardness and elastic have same evolutions with an increase of cerium content from 0 to $0.01 \mathrm{M}$. So, cerium addition leads to harder structures by increasing the rigidity of the systems. Then, values decrease above a cerium content of $0.01 \mathrm{M}$.

These results are particularly interesting because they show an excellent correlation of the evolution of the barrier effect (Figs. 3 and 4) and mechanical properties with the increase in cerium concentration into the sol. Thus, we show here that intrinsic mechanical and physical barrier properties of coatings are connected. In order to understand this feature, in depth structural studies of the hybrid network modifications induced by addition of different cerium quantity were carried out by solid state NMR analyses on the unsupported films.

\subsection{Structural characterization}

\subsubsection{Study of ASB influence for GPTMS}

Fig. 6 shows ${ }^{13} \mathrm{C}$ NMR spectra for unsupported hybrid films with GPTMS and GTPMS/ASB molar ratios of 5. These xerogels underwent the same drying treatment used for hybrid coating on aluminum $\left(110^{\circ} \mathrm{C} / 24\right.$ hours). The assignments of the peaks, discussed in the following section, are shown on the scheme which represents GPTMS formula (Fig. 7). The signals due to the carbon atoms in the GPTMS molecules labeled from 1 to 6 can be recognized in the spectrum of GPTMS without ASB, especially those due to the epoxy rings at $44 \mathrm{ppm}$ (6) and $51 \mathrm{ppm}$ (5). A remarkable feature is the broad peak of the $\mathrm{CH}_{2}$ groups close to silicon atoms (peaks (1) and (2)) with the presence of ASB. These broads, as a result of a larger distribution of $C$ sites, are due to an increase in the network reinforcement [42].

In the present work, evaluation of the ring opening reaction in GPTMS-ASB was done by comparing the signal of the epoxide ring peaks (5) and (6). These peaks due to the epoxy ring carbons have

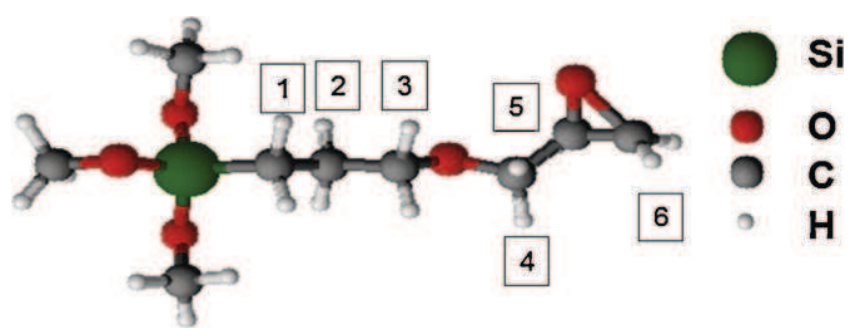

Fig. 7. GPTMS formula. 
A<smiles>COCC(O)OCCC[Si](OC)(OC)OC</smiles>

B<smiles>CO[Si](CCCOCC(O)CO)(OC)OC</smiles><smiles>CCOC(COCCC[Si](=O)(OC)OC)COCOC</smiles>

Fig. 8. Schemes of the different possibilities to open epoxy ring.

not been observed, suggesting that the epoxy rings have been opened. It has been showed by different authors [42-44] that different complex reactions of the silane group lead to the opening of the epoxy rings in GPTMS. The mean chemical reactions involved in this process are displayed in Fig. 8. First, the ring can be opened by methanol produced by the hydrolysis of the silicon alkoxide leading to the formation of methylether (A). Second, water can convert the epoxy group in acidic conditions, thereby yielding a diol (B). The third and last possibility is the reaction of oxirane with another epoxy ring, resulting in oligo or poly(ethylene) oxide derivated (C). In the present work, evaluation of the ring opening reaction in ASB/GPTMS system (Fig. 6) reveals the presence of two new peaks which corresponds to diol formation (peak B $64.54 \mathrm{ppm}$ ) and poly(ethylene) oxide (peak C $71.9 \mathrm{ppm}$ ).

The ${ }^{29} \mathrm{Si}$ NMR spectra of GPTMS and GTPMS/ASB shown in Fig. 9 allow to follow the silane polymerization degree. The ${ }^{29} \mathrm{Si}$ spectrum presents the resonance signals at $-49,-59$, and $-67 \mathrm{ppm}$, assigned to the trifunctional unit interconnected

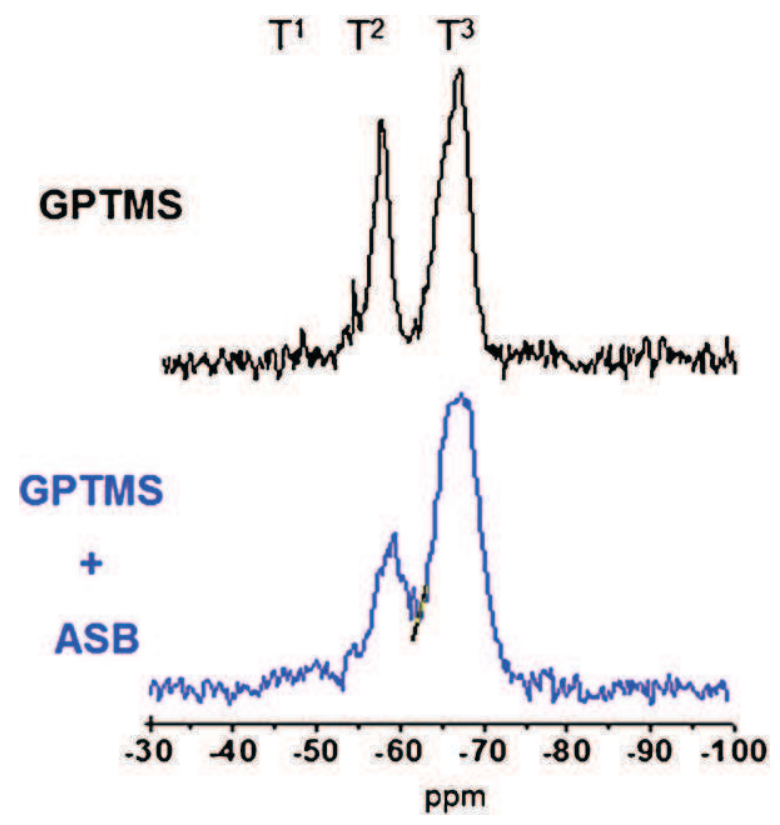

Fig. 9. ${ }^{29}$ Si MAS/NMR spectra of hybrids: GPTMS and GPTMS/ASB.
Table 2

Results of the simulation of ${ }^{29} \mathrm{Si} \mathrm{NMR} \mathrm{spectra} \mathrm{of} \mathrm{Fig.} 12$ and density measurement by helium pycnometry for GPTMS and GPTM/ASB xerogels.

\begin{tabular}{llllll}
\hline Sample & $T^{1}$ & $T^{2}$ & $T^{3}$ & $\tau(\%)$ & Density $\left(\mathrm{g} \mathrm{cm}^{-3}\right)$ \\
\hline GPTMS & 0 & 0.41 & 0.59 & 86.4 & $1.64 \pm 0.02$ \\
GPTMS/ASB & 0 & 0.30 & 0.70 & 90.03 & $1.79 \pm 0.05$ \\
\hline
\end{tabular}

through the oxygen atoms to 1,2 and 3 silicon neighboring denoted by $T^{1} \mathrm{RSi}(\mathrm{OSi})(\mathrm{OH})_{2}, T^{2}\left(\mathrm{RSi}(\mathrm{OSi})_{2}(\mathrm{OH})\right.$ and $T^{3}\left(\mathrm{RSi}(\mathrm{OSi})_{3}\right)$ (Fig. 10). The proportions of $T^{j}$ species present in the samples were obtained from a peak deconvolution program based on each peak area. The polycondensation degree $\tau$ of the silane based inorganic was calculated from the proportion of each specie $T^{j}$, in agreement with the equation: $\tau=\left(T^{1}+2 T^{2}+3 T^{3}\right) / 3 \times 100$. The polycondensation percentages obtained for GPTMS and GPTMS/ASB were of 86.4 and $90.01 \%$ respectively (Table 2 ). The ${ }^{29} \mathrm{Si}$ NMR measurements show a higher reticulation of inorganic network of GPTMS when ASB was added into the hybrid silane matrix.

Density measurements for these two xerogels (GPTMS and GPTMS/ASB) were determined by helium pycnometry and also reported in Table 2. It can be noted that presence of ASB increases the gel density from 1.63 to $1.79 \mathrm{~g} \mathrm{~cm}^{-3}$. So we can correlate the gel density and network reticulation because ASB amount increased the polycondensation percentage of gel and at the same time its density.

\subsubsection{Effect of cerium addition ion on the hybrid structure}

Fig. 11 shows the ${ }^{13} \mathrm{C}$ NMR spectra of the gel (GPTMS/ASB) with different cerium contents. There is a slight broad peak (1) and (2) of the $\mathrm{CH}_{2}$ groups close to silicon atoms when cerium concentration increases; as presciently this phenomenon can be correlated to a higher network densification. Another remark can be made on the epoxy ring opening: there is an increase of the peaks area ratio $\mathrm{C} / \mathrm{B}$ which corresponds to the formation of poly(ethylene) oxide. Therefore, higher cerium concentrations into the hybrid system promote organic polymerization during the epoxy ring opening.

Fig. 12 shows the ${ }^{29} \mathrm{Si}$ NMR spectra of the gel (GPTMS/ASB) prepared with different cerium contents. There are two different ranges of cerium concentration, first between 0 and $0.01 \mathrm{M}$ with a slight decrease of the ratio $T^{3} / T^{2}$; the second range is noted between 0.01 and $0.1 \mathrm{M}$ when the ratio $T^{3} / T^{2}$ greatly increases. This evolution of the silane polycondensation degree $\tau$ as a function of cerium concentration is clearly observed in Fig. 13. It is very interesting to determine the same threshold cerium concentration of $0.01 \mathrm{M}$, previously underlined for the performance of the hybrid coating. A significant collapse of corrosion protection efficiency and mechanical properties was also observed when cerium was incorporated into the hybrid coating at a content higher than $0.01 \mathrm{M}$. It is shown in this section, that cerium favors, on one hand, the opening of the epoxide cycle and the polymerization of the organic part of hybrid and on the other hand, the decrease of polycondensation and the formation of a ramified inorganic network $\mathrm{Si}-\mathrm{O}-\mathrm{Si}$. So, for the low cerium
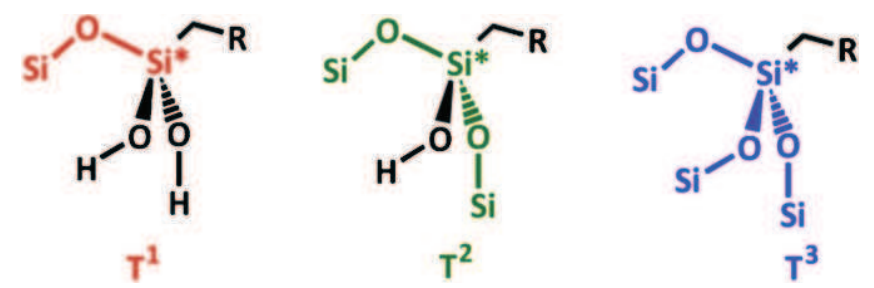

Fig. 10. Schemes of $T$ species. 


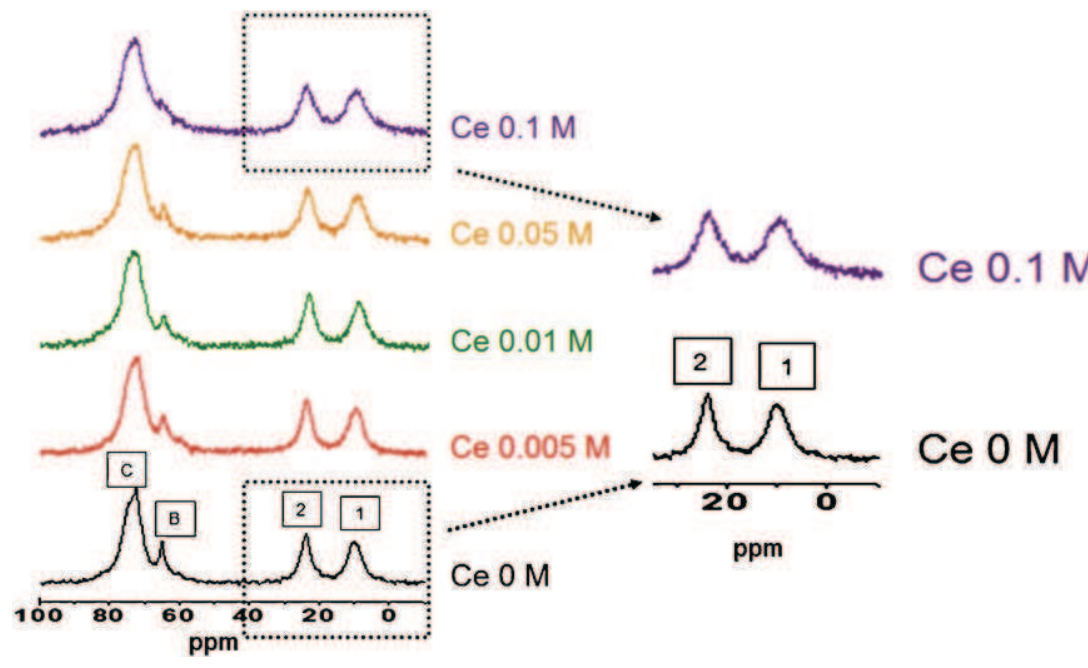

Fig. 11. ${ }^{13} \mathrm{C}$ MAS/NMR spectra of hybrids with different cerium contents.

concentrations, both phenomena contribute to the formation of the hybrid network. However beyond $0.01 \mathrm{M}$, these two phenomena are competitive and can generate internal constraints into the hybrid network due to the increase formation polyhedral cyclic structure. In fact the absence of terminal $T^{1}$ units and the decrease of $T^{2}$ quantities coupled to the increase of $T^{3}$ amount evidence that the addition of cerium favors the conversion of the incompletely condensed silanol cage, like $\mathrm{R}_{7} \mathrm{Si}_{7} \mathrm{O}_{9}(\mathrm{OH})_{3}$, to fully condensed $\mathrm{T}_{8}\left(\mathrm{R}_{8} \mathrm{Si}_{8} \mathrm{O}_{12}\right)$ [45,46]. As consequence, the $\mathrm{H}$-bonding between the ether type oxygen of poly(ethylene) oxide organic chain and polyhedral cyclic silane lead to a decrease of the compatibility between both organic and inorganic parts.

${ }^{27} \mathrm{Al}$ NMR was finally performed to determine what kinds of aluminum species are present in the hybrid material. For the hybrid system without cerium, there are two different coordinated aluminum species. Tetrahedrally (at $54 \mathrm{ppm}$ ) and octahedrally (at $5 \mathrm{ppm}$ ) coordinated aluminum species are present. The six-coordinated aluminum $\left(\mathrm{Al}^{\mathrm{VI}}\right)$ can be attributed to aluminumoxohydroxo complexes $\mathrm{AlO}_{x}(\mathrm{O}-$ $\mathrm{H})_{y}\left(\mathrm{H}_{2} \mathrm{O}\right)$. In alumino silicate gels, the four-coordinated aluminum $\left(\mathrm{Al}^{\mathrm{IV}}\right)$ is normally attributed to the most stable

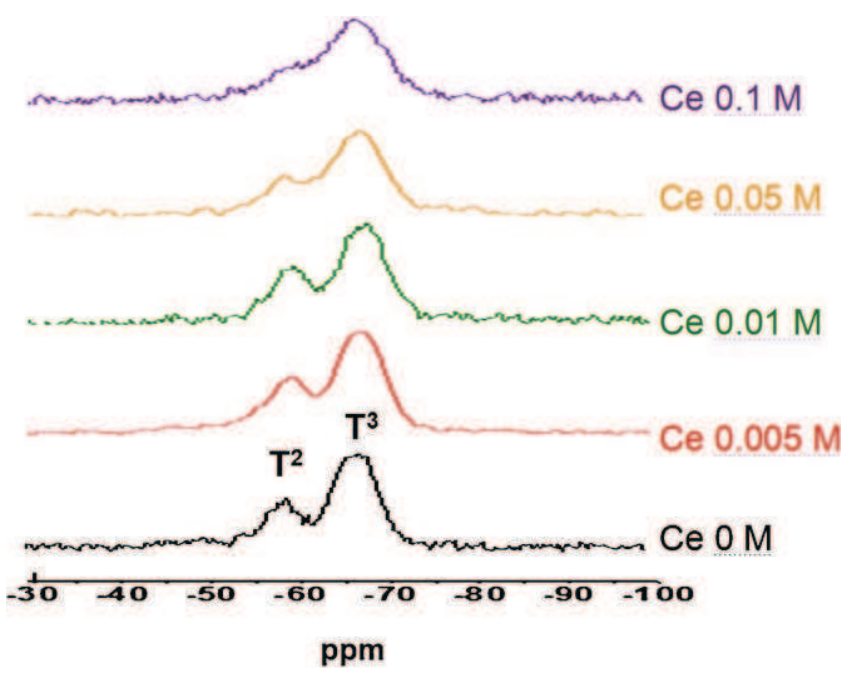

Fig. 12. ${ }^{29} \mathrm{Si}$ MAS/NMR spectra of hybrids with different cerium contents. aluminum atoms in the network Si-O-Al [42,47-49]. Fig. 14 shows the ${ }^{27} \mathrm{Al} \mathrm{NMR}$ spectra of the gel (GPTMS/ASB) with different cerium contents. It can be still observed the same two concentration ranges found by ${ }^{29} \mathrm{Si}$ NMR; for cerium content range from 0 to $0.01 \mathrm{M}$ there is no modification of $\mathrm{Al}^{\mathrm{IV}}$ and $\mathrm{Al}^{\mathrm{VI}}$ proportion into the hybrid material. But, for cerium content in the range $0.01-0.1 \mathrm{M}$ there is a progressive increase of the ratio $\mathrm{Al}^{\mathrm{IV}} / \mathrm{Al}^{\mathrm{VI}}$, so aluminum atoms have been more easily incorporated into the silicon network to form $\mathrm{Al}-\mathrm{O}-\mathrm{Si}$ bonds. This incorporation of aluminum in the inorganic part of hybrid could lead to a hardening of the system and the mobility of the silicon units is reduced which explains the important collapse of electrochemical performances and mechanical properties of the coating with cerium content up to $0.01 \mathrm{M}$. In this case, cerium ions are mainly acting as a network modifier but taking into account their valence, they can play a role on charge valence.

For a concentration range from 0 to $0.01 \mathrm{M}$, cerium promotes both organic and inorganic polymerization. For a higher content, cerium atom may generate internal stresses with its higher atomic radius in the network hybrid and under these conditions, the aluminum substitution in inorganic network $\mathrm{Si}-\mathrm{O}-\mathrm{Si}$ is made easier. These organic and inorganic phase modifications can lead to a porosity creation with free volumes in the hybrid.

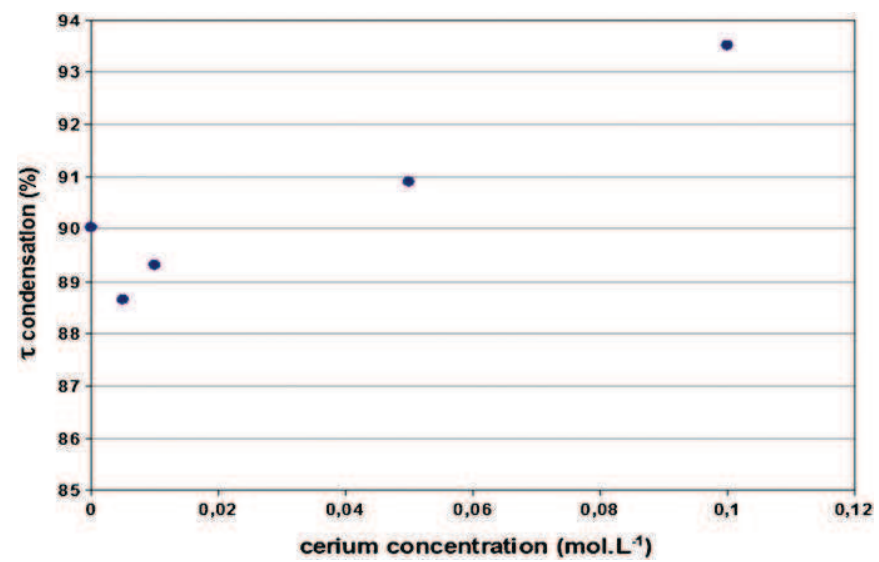

Fig. 13. Condensation rate $\tau$ of hybrid gels with different concentrations of cerium. 


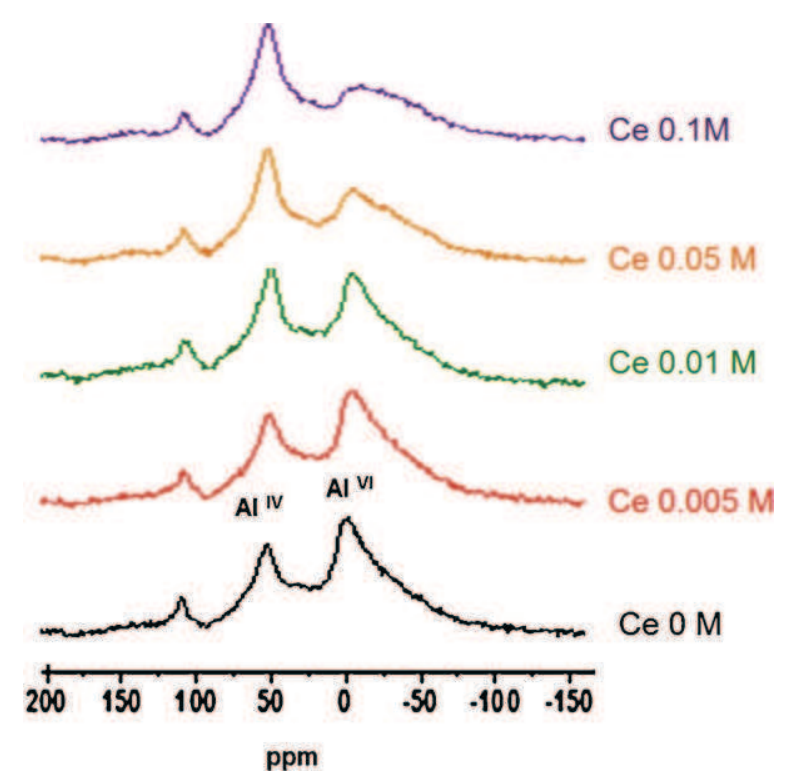

Fig. 14. ${ }^{27} \mathrm{Al}$ MAS/NMR spectra of hybrids with different cerium contents.

\section{Conclusion}

Crack free organic-inorganic coatings were deposited onto AA 2024-T3 aluminum alloy from sols prepared by mixing GPTMS and ASB with different cerium contents $(0-0.1 \mathrm{M})$. The influence of the inhibitor concentration on anti-corrosion and mechanical properties of hybrid sol-gel coating has been investigated. An optimal cerium concentration of $0.01 \mathrm{M}$ has been determined, while for higher cerium concentrations a significant collapse of coating electrochemical performances has been noted. The results of NMR evidenced the effect of cerium content on the hybrid structure: for a concentration higher than $0.01 \mathrm{M}$, there are important modifications of the organic and inorganic polymerization rates and of the aluminum incorporation into the silicon network. These important structural modifications could explain the important collapses of coating performances when it is deposited on aluminum alloy.

It could be inferred that for Ce content lower than $0.01 \mathrm{M}$ the important increase of the organic polymerization and the moderate increase of the inorganic polymerization leads to a higher stiffness of the coating, with an increase in the mechanical properties $E$ and $H$ with the barrier effect. With Ce content higher than $0.01 \mathrm{M}$, the rise of the inorganic polymerization leads to a higher condensation rate which could cause a destabilization of the $\mathrm{Si}-\mathrm{O}-\mathrm{Si}$ (Ce atomic radius are higher than the one of $\mathrm{Si}$ ) with a possible creation of free volumes into the hybrid and involves a collapse of the coating performances. In prospect, it would be very interesting to analyze these sol-gel coatings with a microscopic technical high resolution in order to observe structural modifications of the hybrid.

\section{References}

[1] ASM Handbook, 10th ed., Properties and Selection: Nonferrous Alloys and Special-Purpose Materials, vol. 2, ASM International Committee Handbook, 1992, p. 1328

[2] A. Collazo, A. Covelo, M. Izquierdo, X.R. Nóvoa, C. Pérez, Prog. Org. Coat. 63(2008) 291.

[3] Z. Szklarska-Smialowska, Corros. Sci. 41 (1999) 1743.

[4] K.A. Yasakau, M.L. Zheludkevich, O.V. Karavai, M.G.S. Ferreira, Prog. Org. Coat. 63 (2008) 352.

[5] M.L. Zheludkevich, R. Serra, M.F. Montemor, I.M. Miranda Savado, M.G.S. Ferreira, Surf. Coat. Technol. 200 (2006) 3084.

[6] M. Guglielmi, J. Sol-Gel Sci. Technol. 8 (1997) 443.

[7] C. Sanchez, B. Julian, P. Belleville, M. Popall, J. Mater. Chem. 15 (2005) 3559.

[8] D. Wang, G.P. Bierwagen, Prog. Org. Coat. 64 (2009) 327.

[9] C. Brinker, G. Frye, A. Hurd, C. Ashley, Thin Solid Films 201 (1991) 97.

[10] Y. Joshua Du, M. Damron, G. Tang, H. Zheng, C.-J. Chu, J.H. Osborne, Prog. Org. Coat. 41 (2001) 226.

[11] R.L. Twite, G.P. Bierwagen, Prog. Org. Coat. 33 (1998) 91.

[12] W.J. van Ooij, D.Q. Zhu, G. Prasad, S. Jayaseelan, Y. Fu, N. Teredesai, Surf. Eng. 16 (2000) 386.

[13] D. Zhu, W.J. van Ooij, Corros. Sci. 45 (2003) 2177.

[14] A. Cabral, R.G. Duarte, M.F. Montemor, M.L. Zheludkevich, M.G.S. Ferreira, Corros. Sci. 47 (2005) 869.

[15] M. Khobaid, L.B. Renolds, M.S. Donley, Surf. Coat. Technol. 140 (2001) 16.

[16] A. Franquet, H. Terryn, J. Vereecken, Appl. Surf. Sci. 211 (2003) 259.

[17] H. Watson, P.J. Mikkola, J.G. Matisons, J.B. Rosenholm, Colloids Surf. Physicochem. Eng. Aspects 161 (2000) 183.

[18] M.F. Montemor, M.G.S. Ferreira, Electrochim. Acta 5 (2007) 6976

[19] B.R.W. Hinton, L. Wilson, Corros. Sci. 29 (1989) 967.

[20] A.E. Hughes, R.J. Taylor, B.R.W. Hinton, L. Wilson, Surf. Interface Anal. 23 (1995) 540

[21] V. Moutarlier, B. Neveu, M.P. Gigandet, Surf. Coat. Technol. 202 (2008) 2052.

[22] V. Palanivel, Y. Huang, W.J.V. Ooij, Prog. Org. Coat. 53 (2005) 153.

[23] M.L. Zheludkevich, I. Miranda Salvado, M.G.S. Ferreira, J. Mater. Chem. 15 (2005) 5099.

[24] S.M. Tamborim, A.P.Z. Maisonnave, D.S. Azambuja, G.E. Englert, Surf. Coat. Technol. 20 (2008) 5991.

[25] W.C. Oliver, G.M. Pharr, J. Mater. Res. 7 (1992) 1564

[26] J. Malzbender, J.M.J.D. Toonder, A.R. Balkenend, G.D. With, Mater. Sci. Eng. 36 (2002) 47-103.

[27] J. Ballarre, E. Jimenez-Pique, M. Anglada, S.A. Pellice, A. Cavalieri, Surf. Coat. Technol. 203 (2009) 3325.

[28] C.H. Tsai, F. Mansfeld, Corros. Sci. 49 (1993) 726.

[29] F. Mansfeld, M.W. Kendig, J. Electrochem. Soc. 135 (1988) 828

[30] S.V. Lamaka, M.F. Montemor, A.F. Galio, M.L. Zheludkevich, C. Trindade, L.F. Dick, M.G.S. Ferreira, Electrochim. Acta 5 (2008) 4773.

[31] M. Kendig, F. Mansfeld, S. Tsai, Corros. Sci. 23 (1983) 317.

[32] D. Raps, T. Hack, J. Wher, M.L. Zheludkevich, A.C. Bastos, M.G.S. Ferreira, O. Nuyken, Corros. Sci. 51 (2009) 1012.

[33] F. Mansfeld, J. Appl. Electrochem. 25 (1995) 187

[34] P.L. Bonora, F. Deflorian, L. Fedrizzi, Electrochim. Acta 4 (1996) 1073.

[35] K. Bonnel, C. Le Pen, N. Pébère, Electrochim. Acta 4 (1999) 4259.

[36] A.M. Cabral, W. Trabelsi, R. Serra, M.F. Montemor, M.L. Zheludkevich, M.G.S Ferreira, Corros. Sci. 48 (2006) 3740.

[37] F. Mansfeld, M.W. Kendig, S. Tsai, Corrosion 38 (1982) 478.

[38] A.S.L. Castela, A.M. Simoes, M.G.S. Ferreira, Prog. Org. Coat. 38 (2000) 1.

[39] L.J. Zhang, J.J. Fan, Z. Zhang, F.H. Cao, J.Q. Zhang, C.N. Cao, Electrochim. Acta 5 (2007) 5325.

[40] S.K. Poznyak, M.L. Zheludkevich, D. Raps, F. Gammel, K.A. Yasakau, M.G.S. Ferreira, Prog. Org. Coat. 62 (2008) 226.

[41] N.C. Rossero-Navarro, S.A. Pellice, A. Duran, M. Aparicio, J. Sol-Gel Technol. 52 (2009) 31.

[42] M. Templin, U. Wiesner, H.W. Spiess, Adv. Mater. 9 (1997) 814

[43] P. Innocenzi, G. Brusatin, F. Babonneau, Chem. Mater. 12 (2000) 3726.

[44] T.L. Metroke, O. Kachurina, E.T. Knobbe, Prog. Org. Coat. 44 (2002) 295.

[45] F.J. Feher, D.A. Newman, J.F. Walzer, J. Am. Chem. Soc. 111 (1989) 1741-1748.

[46] C.V. Santilli, V.H.V. Sarmento, K. Dahmouche, S.H. Pulcinelli, A.F. Craievich, J. Phys. Chem. 13 (2009) 14708-14714.

[47] A.D. Irwin, J.S. Holmgren, J. Jonas, J. Mater. Sci. 23 (1988) 2908.

[48] F. Babonneau, S. Dire, L. Bonhomma-Coury, J. Livage, in: P. Wisian-Neilson, H.R Allcock, J.K. Wynne (Eds.), Inorganic and Organometallic Polymer II, vol. 574 1994, p. 134

[49] M.M. Amini, Z. Mehraban, S.J.S. Sabounchei, Mater. Chem. Phys. 78 (2002) 81. 